\title{
EVALUATION OF THE RESULTS OF ANTERIOR CRUCIATE LIGAMENT RECONSTRUCTION USING FLEXOR TENDONS AND RIGID GUIDE TRANSVERSE SCREW
}

Renato Luiz Bevilacqua de Castro', Sandor Dosa Acras²

\section{ABSTRACT}

Objective: The aim of this study was to analyze the results of ACL (anterior cruciate ligament) reconstruction using quadruple flexor tendons as grafts, with ligament fixation in the femur using a rigid guide transverse screw and in the tibia, using a cancellous screw with a fixing washer. Methods: 173 knees (166 from males and seven from females) that had undergone surgery with ACL reconstruction using this technique between December 2002 and February 2007 were evaluated. The mean age was 30 years (from 13 to 56 years), and the mean follow-up time was 30 months (6-55 months). We divided the knees into three groups, which were assessed using the Lysholm scale: Group A with six months of followup; Group B with 12 months of follow-up; and Group C with 24 months of follow-up. Results: We evaluated the results, and groups A, B and C received 94, 95 and 95 points respectively on the Lysholm scale. Conclusions: The surgical technique proved to be safe and easy to perform, with good results and a low complication rate. Also, its results were maintained throughout the study period of 24 months.

Keywords - Knee; Anterior Cruciate Ligament; Arthroscopy

\section{INTRODUCTION}

The anterior cruciate ligament (ACL) is an important ligament of the knee and accounts for $86 \%$ of anterior stabilization. Lesion of the ACL is more common among individuals who practice sports, mainly affecting young adults ${ }^{(1-3)}$. One of the worst consequences of this pathology is the development of arthrosis as the disease evolves.

Various techniques, grafts and fixation materials have been used, but there is no consensus as to the best ones.

One of the most commonly used techniques for ACL reconstruction still is the fixation of the central third of the patellar ligament with interference screws; but some problems are frequently reported with this technique, such as: anterior knee pain, decreased strength of the extensor muscle, shortening of the patellar ligament and lesion of the plexus saphenous ${ }^{(4,5)}$.

Since the 1980s, the flexor tendons have been used in Brazil, and have been reported by various authors. Quadruple semitendinosus and gracilis tendon graft is one of the strongest grafts available, resisting tensions of between 4300 and $4600 \mathrm{~N}$; far more resistant than the ACL itself, which can bear up to 1725 to $2169 \mathrm{~N}$ and the $10 \mathrm{~mm}$ patellar tendon, with a limit of resistance of between 2071 and $2977 \mathrm{~N}^{(7,8)}$. It is important to remember that one year after the surgical procedure, the grafts lose half of their mechanical resistance, which makes quadruple semitendinosus and gracilis tendon graft the option that is more resistant than the ACL itself $f^{(7,9,10)}$.

1 - Coordinator of the Orthopedics and Traumatology Service of the Hospital Maternidade de Campinas, São Paulo, Brazil.

2 - Assistant Doctor of the Orthopedics and Traumatology Service of the Hospital Maternidade de Campinas, São Paulo, Brazil.

Work carried out at the Hospital Maternidade de Campinas.

Correspondence: Av. Barão de Itapura, 3.378 - 13076-000 - Campinas, SP, Brazil. E-mail: renatojoelho@terra.com.br

Work received for publication: October 29, 2009; accepted for publication: December 3, 2009. 
The excellence of the quadruple semitendinosus and gracilis tendon graft has led to the development of various surgical techniques in the past, but the fixation methods were either too elastic, or else they did not match up to the extra-articular fixations in terms of strength ${ }^{(11)}$.

This paper demonstrates the surgical technique of reconstruction of the anterior cruciate ligament with transverse screw and graft of the knee flexors (semitendinosus and gracilis) using the rigid guide. The use of the rigid guide emerged as another option to replace the use of flexible guides for traction of the graft to the femoral site. Traction of the graft with a flexible guide has always raised fears of laceration of the graft, particularly when the diameter of the graft is equivalent to that of the bone tunnel ${ }^{(12)}$.

From December 2002 we began to use the Transloc ${ }^{\circledR}$ femoral fixation screw with rigid guide and cancellous screw with washer, in tibial fixation (Figure 1).

Femoral fixation of the rigid guide transverse screw prevents laceration of the graft and has resistance to tear of around $1112 \mathrm{~N}$, while the Endobutton ${ }^{\circledR}$ has resistance of $1086 \mathrm{~N}$, and absorbable and metallic interference screws have resistance of $589 \mathrm{~N}$ and $546 \mathrm{~N}$, respectively ${ }^{(13-16)}$.

Our objective in this paper is to analyze the reconstruction of the anterior cruciate ligament with a transverse femoral screw, which uses a rigid guide wire.

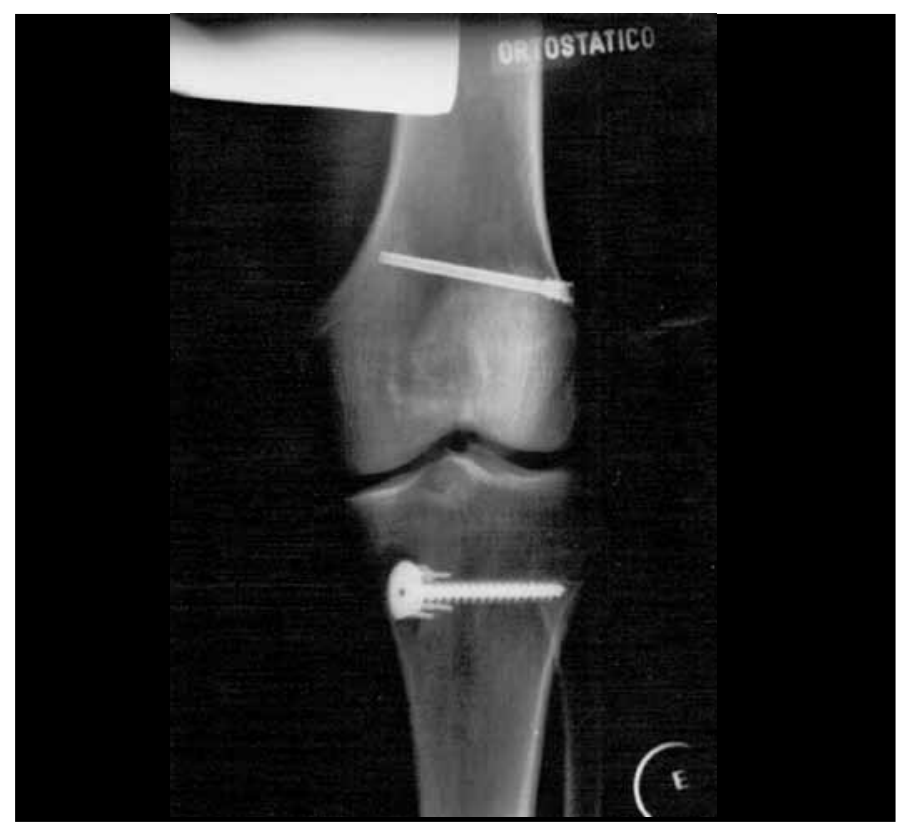

Figure 1 - Transloc $^{\circledR}$ femoral fixation screw with rigid guide and cancellous screw with washer in the tibial fixation.

\section{MATERIAL AND METHOD}

In the period of December 2002 to February 2007, we had the opportunity to perform this method, and to include 176 knees in the group to be evaluated. The criteria for inclusion of these patients were: age below 60 years, no previous knee surgeries, no bilateral lesion of the anterior cruciate ligament or need for concomitant surgeries, such as: osteotomies, major meniscectomies or chondral procedures like mosaicplasty or microfracture. The patients were operated on at the Hospital Maternidade de Campinas and submitted to ACL reconstruction with the tendons of the knee flexor muscles, fixed with a transverse screw in the femur and fixation screw and washer in the tibia. Three patients who failed to turn up for the evaluation on the date of their appointment were excluded. We analyzed 173 knees (173 patients), 166 male and seven female, with a mean age of 30 years (13 to 56 years) and mean follow-up time of 30 months (6-55 months).

The patients were evaluated by the Lysholm scale after surgery, forming three groups: A, with 6 months of follow-up (173 patients); B, with 12 months of follow-up (160 patients); and C, with 24 months of follow-up (106 patients).

\section{The surgical technique}

We began the surgery with a proximal and medial incision of approximately $5 \mathrm{~cm}$ in the leg, at the insertion point of the flexor tendons in the tibia. We opened the fascia of the sartorius muscle and dissected the insertion of the semitendinosus and gracilis tendons. We sectioned the natural tendon adherences, particularly the semitendinosus, and removed the tendinous graft with a tendon extractor after sectioning it in the tibial insertion. On a surgical table, we prepared the graft with an overlock stitch using number 2 Ethibond $^{\circledR}$ thread at the flatter end and number 5 Ethibond $^{\circledR}$ thread at the cylindrical end. We carried out a total arthroscopy of the knee, first examining the whole joint and correcting possible meniscal and chondral lesions. To prepare the tibial tunnel, we used a guide with cannula, placed 3 to $4 \mathrm{~cm}$ below the joint line in the tibial metaphysis, medially to the tibial tubercle, taking advantage of the incision made to remove the tendinous graft. The intra-articular end of the guide is positioned on the site of tibial origin of the anterior cruciate ligament, 2 to $3 \mathrm{~mm}$ from the fibers of the 
posterior cruciate ligament. The cannula of the tibial guide is placed at a $45^{\circ}$ angle to the longitudinal axis of the tibia, and the angle between the initial point of the tibia tunnel and the horizontal arm of the guide is fixed at $55^{\circ}$, to produce an ideal orientation for the transtibial femoral perforation. With the guide in position, the tibia is perforated with a Kirshner wire, and a reamer with equal diameter to that of the tendinous graft makes the tibial tunnel, guided by the intraosseous wire. The femoral tunnel is prepared with the knee flexed at $90^{\circ}$. We used a transtibial guide, positioned on the medial side of the lateral condyle of the femur at 10 o'clock for the left knee and at 2 o'clock for the right knee, $2 \mathrm{~mm}$ from the posterior cortical wall. With the guide in position, the femur is perforated with a Kirshner wire, which guides a reamer of the same diameter as the tendinous graft, producing a femoral tunnel of $3.5 \mathrm{~cm}$ in depth.

Through the tibial tunnel, we introduced a rigid U-shaped guide (Figure 2) which carries a number 2 Ethibond $^{\circledR}$ thread in the form of a loop to the end of the femoral tunnel, keeping the two ends of the wire outside the tibial tunnel. The extra-articular portion of the rigid guide positions a cannula for perforation of the lateral condyle, so that a Kirshner wire passes inside the loop of the number 2 Ethibond $^{\circledR}$ thread inside the femoral tunnel. The number 5 and number 2 Ethibond ${ }^{\circledR}$ threads sutured to the graft of semitendinosus and gracilis tendons are tied to one end of the Ethibond ${ }^{\circledR}$ looped thread. Next, they are tractioned so that they enter the tibial tunnel and then the femoral tunnel, passing over the Kirshner wire and returning

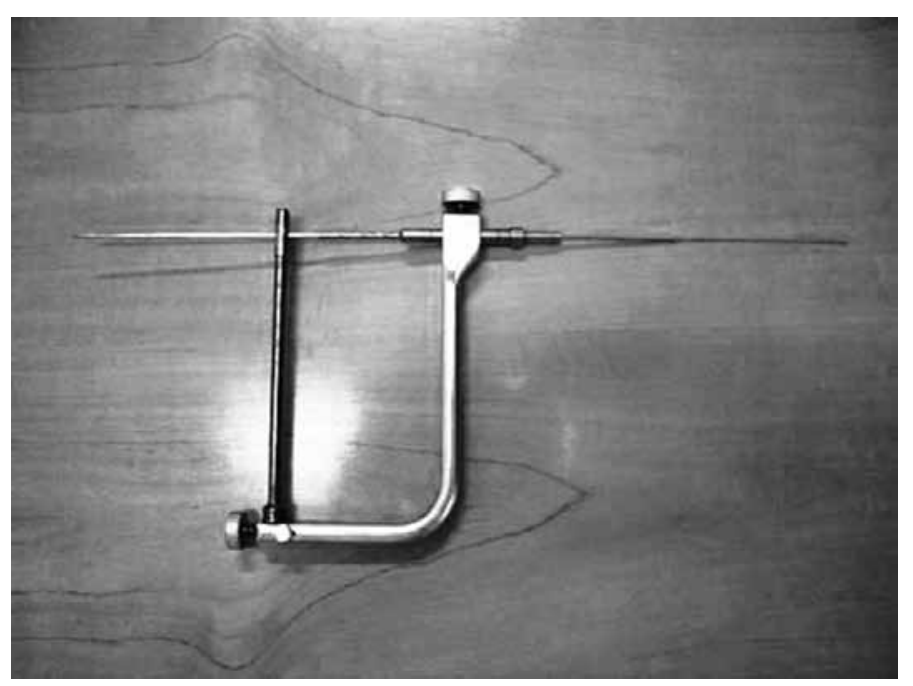

Figure 2 - Femoral rigid guide. to the tibial tunnel, leaving the two free ends of the tendinous graft outside the tibial tunnel. Using the Kirshner wire located in the lateral condyle, we introduced the cannulated transverse screw. In the tibia, we performed scarification of the cortical wall in the external opening of the tibial tunnel, and we fixed the graft of the semitendinosus and gracilis tendons with a spiked washer, fixed with a cancellous screw that goes through both cortical walls.

We used the Accelerated Rehabilitation Protocol proposed by Shelbourne and Nitz ${ }^{(17)}$.

\section{RESULTS}

After evaluation of the results and analysis through the Lysholm scale, groups A (six months postoperative), B (12 months postoperative) and C (24 months postoperative) scored 94 (61-100), 95 (65-100) and 95 (64-100) points, respectively (Figure 3).

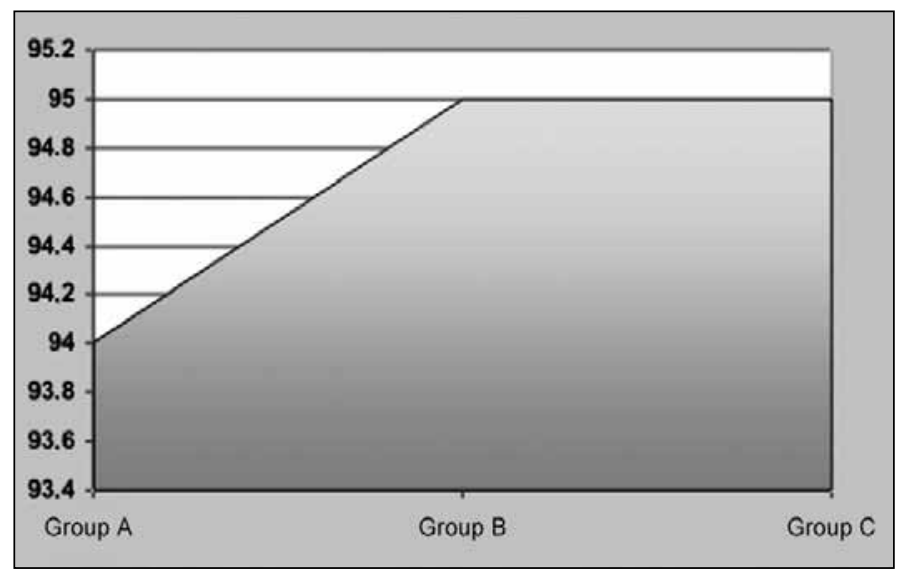

Figure 3 - Results of the Lysholm scale for groups A (6 months postoperative), B (12 months postoperative) and C (24 months postoperative).

\section{Complications}

In terms of complications, we had four cases of loosening of the femoral screw; one was removed in the fifth month postoperative, but did not influence the surgical result (Figure 4) and three were removed in the late postoperative period, at 17, 21 and 30 months, which were removed due to the patients' complaints of discomfort in the side of the thigh, but neither of these did influence the surgical result.

We also had two superficial dehiscences in the tibial incision, which were treated without removing the screw, with good results. 


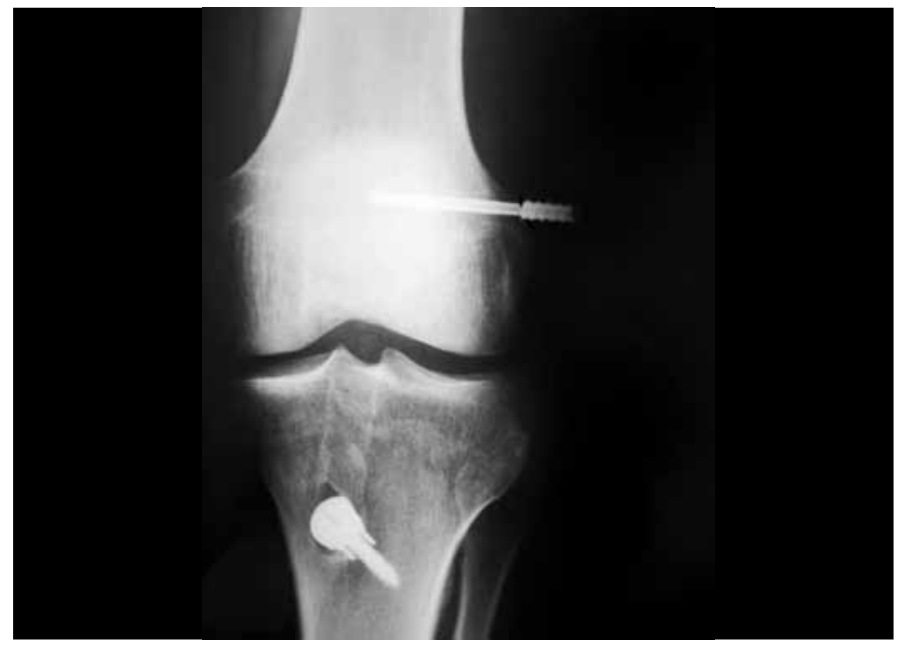

Figure 4 - Loosening of the femoral screw in the fifth month postoperative.

\section{DISCUSSION}

Reconstruction of the anterior cruciate ligament with quadruple flexor tendon graft has become popular over the years, and does not present a high level of complications in the donor site, like reconstruction with patellar tendon graft.

The flexor tendons also have other advantages over alternative types of graft, such as a larger surface area, which facilitates the spread of nutrients and revascularization $^{(18)}$. They offer safety in terms of traction strength, with tear resistance of 4300 to $4600 \mathrm{~N}$, making them much more resistant than the ACL itself, which can withstand up to 1725 to $2169 \mathrm{~N}$, and the patellar tendon, which has a tear resistance of 2071 to $2977 \mathrm{~N}^{(7,8)}$.

The use of the flexor tendon graft has always seemed a good initiative, and in Brazil, various authors have demonstrated techniques, such as Gomes and Marczyk $^{(19)}$ in 1981.

Camanho and Olivi(20) and Krause et $\mathrm{al}^{(11)}$ demonstrated fixation of the flexor tendon graft using the Endobutton ${ }^{\circledR}$ technique; but the rigidity necessary for the fixation was not known, and the Endobutton ${ }^{\circledR}$ graft structure generates the "elastic recoil phenomenon", which can produce longitudinal movement of the graft inside the tunnels ${ }^{(18)}$.

In 1996, Howell and Gottilieb ${ }^{(21)}$ demonstrated good results with fixation of the flexor tendon graft using a transverse screw in the femur and a cancellous screw and washer in the tibia (Figure 5), increasing the rigidity of the structure. In this technique, although of good mechanical quality, the graft is passed and guided by direct vision in the femoral tunnel, which can present some technical difficulty, particularly at the start of the surgeon's learning curve.

Other femoral transverse fixation techniques soon appeared, aimed at presenting a more practical and easier technique. One such example is TransFix ${ }^{\circledR}$ which was demonstrated in Brazil by Zekcer et $\mathrm{al}^{(22)}$ and other implants that traction the graft through a flexible guide wire. This type of traction places tension on the graft through the tibial and femoral tunnels, and can present some complications, particularly when the tunnel is very narrow. The main cause of these complications was the lack of total proximal migration of the graft, which can cause the tendon, or the flexible wire, to rupture ${ }^{(12)}$. To develop this concept, rigid guide transverse screws appeared, with the advantage of protecting the graft from the traction of the flexible wire guide. The main difference between the rigid guide and the flexible wire guide is that the first enables the graft to pass through the bone tunnels by longitudinal traction, while the second requires a flexible metallic wire to traction the graft, which can generate sufficient force to tear the graft or break the wire ${ }^{(12)}$.

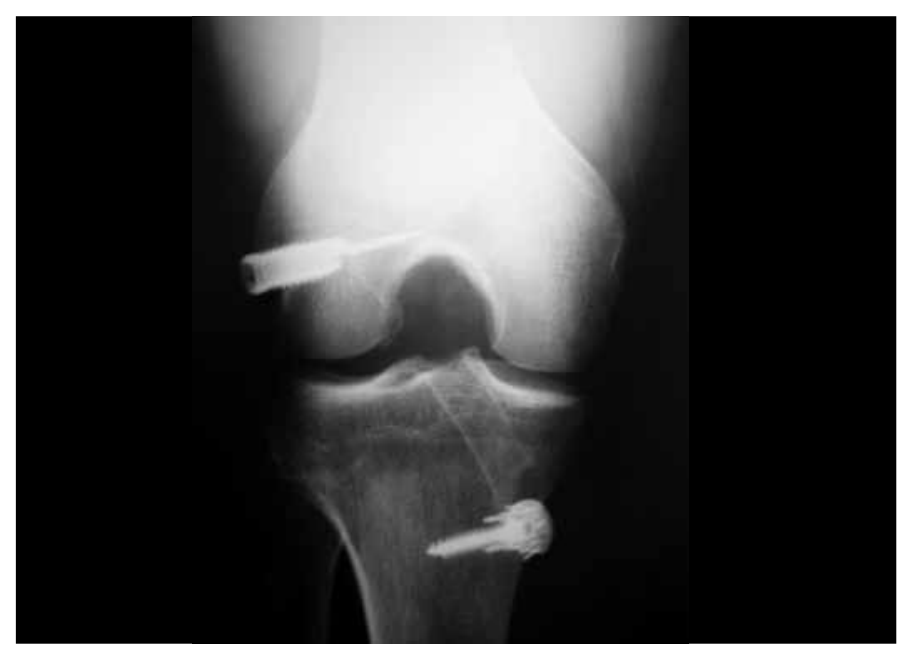

Figure 5 - Bone Mulch transverse screw.

We began our case studies in 2002 and analyzed a population that was reevaluated through the Lysholm scale at 6, 12 and 24 months, in which groups A (6 months postoperative), B (12 months postoperative) and C (24 months postoperative) scored 94, 95 and 95 points, respectively. These data corroborate those of the literature, Taylor et $\mathrm{al}^{(23)}$ and Gorschewsky et $\mathrm{al}^{(24)}$ demonstrated similar results using the flexor tendon graft analyzed by the Lysholm scale. Our data showed 
that using the technique, the results are maintained for 24 months, and that the surgical technique is easy to perform. The surgical technique also seemed to us to be very safe, in terms of the risk of laceration of the graft.

We had one complication in the fifth month postoperative, with partial loosening of the femoral screw. On physical examination, the knee was stable and we confirmed the good state of the neoligament through magnetic resonance imaging (Figure 6), and clinically, the patient obtained good results in the postoperative period, successfully resuming the practice of sports. We also had another three loosenings of the femoral screw in the late postoperative period. These screws were removed and did not cause damage to the knee, as they were not intra-articular and they did not influence the surgical result.

\section{CONCLUSIONS}

Reconstruction of the anterior cruciate ligament with flexor tendons and rigid guide femoral transverse screw is a safe surgical technique, which is easy to

\section{REFERENCES}

1. Butler DL, Noyes FR, Grood ES. Ligamentous restraints to anterior-posterior drawer in the human knee. A biomechanical study. J Bone Joint Surg Am. 1980;62(2):259-70.

2. Grood ES, Suntay WJ, Noyes FR, Butler DL. Biomechanics of the knee-extension exercise. Effect of cutting the anterior cruciate ligament. J Bone Joint Surg Am. 1984;66(5):725-34.

3. Fukubayashi T, Torzilli PA, Sherman MF, Warren RF. An in vitro biomechanical evaluation of anterior-posterior motion of the knee. Tibial displacement, rotation and torque. J Bone Joint Surg Am. 1982;64(2):258-64.

4. Bonamo JJ, Krinick RM, Sporn AA. Rupture of the patellar ligament after use of its central third for anterior cruciate reconstruction. A report of two cases. Bone Joint Surg Am. 1984;66(8):1294-7

5. Noyes FR, Mangine RE, Barber SD. The early treatment of motion complications after reconstruction of the anterior cruciate ligament. Clin Orthop Relat Res. 1992;(277):217-28.

6. DeLee JC, Craviotto DF. Rupture of the quadriceps tendon after a central third patellar tendon anterior cruciate ligament reconstruction. Am J Sports Med 1991;19(4):415-6.

7. Cooper DE, Deng XH, Burstein AL, Warren RF. The strength of the centra third patellar tendon graft. A biomechanical study. Am J Sports Med 1993;21(6):818-23.

8. Hamner DL, Brown CH Jr, Steiner ME, Hecker AT, Hayes WC. Hamstring tendon grafts for reconstruction of the anterior cruciate ligament: biomechanical evaluation of the use of multiple strands and tensioning techniques. J Bone Joint Surg Am. 1999;81(4):549-57.

9. Noyes FR, Butler DL, Grood ES, Zernicke RF, Hefzy MS. Biomechanical analysis of human ligament grafts used in knee-ligament repairs and reconstructions. J Bone Joint Surg Am. 1984;66(3):344-52.

10. Woo SL, Hollis JM, Adams DJ, Lyon RM, Takai S. Tensile properties of the human femur-anterior cruciate ligament-tibia complex. The effects of specimen age and orientation. Am J Sports Med. 1991;19(3):217-25.

11. Krause R, Camanho G, Krause M. Reconstrução do LCA: pré-tensionamento "in situ" do semitendíneo triplo. Rev Bras Ortop.1998;33(5):363-7.

12. Lee YS, Ahn JH, Kim JG, Park JH, Park JW, Kim CB, Lee SW. Analysis and prevention of intra-operative complications of TransFix fixation in anterior cruciate ligament reconstruction. Knee Surg Sports Traumatol Arthrosc. 2008;16(7):639-44.

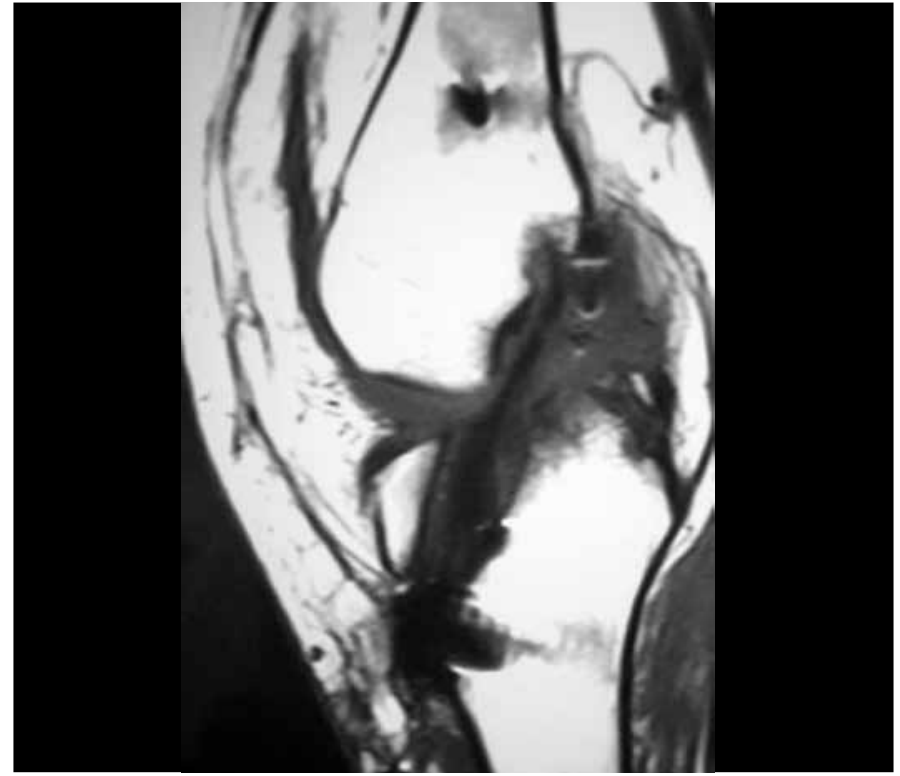

Figure 6 - Good state of neoalignment shown through magnetic resonance, in the fifth month postoperative.

perform, with good results and a low rate of complications, and the results were maintained throughout the 24-month period of the study.

13. Milano G, Mulas PD, Ziranu F, Piras S, Manunta A, Fabbriciani C. Comparison between different femoral fixation devices for ACL reconstruction with doubled hamstring tendon graft: a biomechanical analysis. Arthroscopy. 2006;22(6):660-8.

14. Fabbriciani C, Mulas PD, Ziranu F, Deriu L, Zarelli D, Milano G. Mechanical analysis of fixation methods for anterior cruciate ligament reconstruction with hamstring tendon graft. An experimental study in sheep knees. Knee. 2005;12(2):135-8.

15. Harilainen A, Sandelin J, Jansson KA. Cross-pin femoral fixation versus metal interference screw fixation in anterior cruciate ligament reconstruction with hamstring tendons: results of a controlled prospective randomized study with 2-year follow-up. Arthroscopy. 2005;21(1):25-33.

16. Goddard RK, Jones HW, Singh BI, Shelton JC, Mowbray MA. Biomechanical properties of 4 methods of fixation used for hamstring acl grafts. J Bone Joint Surg Br. 2006;88:379.

17. Shelbourne KD, Nitz P. Accelerated rehabilitation after anterior cruciate ligament reconstruction. Am J Sports Med. 1990;18(3):292-9.

18. Larson RV, Ericksen D. Complications in the use of hamstring tendons for anterior cruciate ligament reconstruction. Sports Med Arthrosc Rev. 1997;5(1):83-90.

19. Gomes JL, Marczyk LR. Reconstrução dos ligamentos cruzados do joelho com o tendão duplo do semitendinoso. Rev Bras Ortop. 1981;16(4):128-32.

20. Camanho GL, Olivi R. O uso do tendão do músculo semitendíneo fixo com "Endobutton ${ }^{\circledR "}$ no tratamento das instabilidades anteriores do joelho. Rev Bras Ortop. 1996;31(5):369-72.

21. Howell SM, Gottilieb JE. Endoscopic fixation of a double-looped semitendinosus and gracilis ACL graft using bone mulch screw. Oper Techn Orthop. 1996;6(3):152-60.

22. Zekcer A, Carneiro AC, Minervini S, Carneiro Filho M. "TransFix" ${ }^{\circledR ”: ~ u m ~ m e ́ t o d o ~}$ de fixação femoral dos tendões flexores na reconstrução do LCA. Relato preliminar. Rev Bras Ortop. 2001;36(9):340-3.

23. Taylor DC, DeBerardino TM, Nelson BJ, Duffey M, Tenuta J, Stoneman PD, Sturdivant RX, Mountcastle S. Patellar tendon versus hamstring tendon autografts for anterior cruciate ligament reconstruction: a randomized controlled trialusing similar femoral and tibial fixation methods. Am J Sports Med. 2009;37(10):1946-57

24. Gorschewsky O, Stapf R, Geiser L, Geitner U, Neumann W. Clinical comparison of fixation methods for patellar bone quadriceps tendon autografts in anterior cruciate ligament reconstruction: absorbable cross-pins versus absorbable screws. Am J Sports Med. 2007;35(12):2118-25. 